\title{
Participatory Approach in Project Management and Developement in Developing Countries
}

\author{
Awa Julius Awa \\ LLB Hons. English Law University of Yaounde II Yaounde Cameroon, Dipl. Project Planning, Management and \\ Evaluation Pan African Institute for Development West African
}

\begin{abstract}
Community development and management in most developing countries especially in Africa has been retarded because the main participants which are the local people have been left out or neglected in the implementation of developmental projects by either governments or some developmental agencies Whereas, participatory approach is a method of conceiving projects in which all the stake holders have a say in decision making which has greatly been the canker-worm of developing countries. They are various types of participatory approaches which may include Rapid Rural Appraisal (RRA), Participatory Rural Appraisal (PRA) and Participatory Assessment Monitoring and Evaluation (PAME) which could be analyzed as appropriate approach in realizing Community's effort in developing countries and stresses the need for integration, participation and empowerment. With the application of these principles, the integration of various stake holders will enhances cross 'sectoral' harmonization of developmental objectives as well as increased coordination between agencies involved in the developmental process. Participation on its part gives the opportunity for consultation with those most directly affected which most at times are rural dwellers in developing countries; hence increasing the level of involvement of local people in the development process (Storey, 1999) and gives community members to take part in identifying priority areas, decision making and vulnerable groups to participate effectively in community development.
\end{abstract}

Keywords: Participation, Management, Project, Approach, Developing, Development, Community

\section{Introduction}

Community development and management in most developing countries in Africa has been retarded because the main participants which are the local people have been left out or neglected in the implementation of developmental projects by either governments or some developmental agencies; in order to empowering the community, members suggest a greater degree of influence being wielded by local residents and this shift in the power balance between "Centre" and "Periphery" and between "Professionals" and "Amateurs" (Storey, 1999). In practice this has resulted to the plethora of initiative which to a greater or lesser extent espouses the idea of a more locally attuned "bottom up" approach to community development stressing the importance of involving local community associations. Thus in order to understand how this participatory approach is important to speed local community development, we will examine the strategies used by SHUMAS. SHUMAS is an African development non Governmental Organization (NGO) based in Bamenda, North West Region of the Republic of Cameroon. This organization started as an informal initiative in 1993 helping to educate deprived children passed to premature adulthood. By June 1996 she formalized her activities focusing on enhancing and promoting sustainable rural development and assisting urban poor. Their policies promotes integrated sustainable rural development and its aim is to improve the overall living standards of poor disadvantaged people in particular women and children and also establishing some basic facilities like schools, social welfare, agriculture, health care, women's issues, forestry and organic farming, adult literacy and many other social amenities .

\section{a) Problem Statement}

Participatory approach is a more sustainable approach in project management because all the stake holder are usually taken into consideration and they participate in all the various phases of the project unlike in the other approaches such as the "Traditional planning approach" whereby professionals carryout almost all activities starting from Needs assessment right up to Evaluation by themselves with very little or no consideration of the views of the beneficiaries and other stake holders. On the other hand in a participatory approach, regardless of the methods of actual participation a large volume of 
qualitative data in plain text format as well as numeric or quantitative data can be generated which tell about people's view, desires, priorities and can also provide much deeper insights into complexities involved. Some of the flaws of the traditional planning approach have been that analyses of some numeric values itself may not be sufficient to identity problems or desired actions to address them. Professionals normally apply their own value judgments in interpreting the results to identified problems which may not necessarily be the ones perceived by the real beneficiaries.

\section{Literature Review}

The concept of project management is a methodical approach to planning and guiding project process from start to finish. According to project management institutes, the processes are guided through five stages; Initiation, Planning, Executing, Controlling and Closing. Project management can be applied to almost any type of project and is widely used to control the complex processes of software development projects. The System Development Life Cycle (SDLC) is one example of a methodology for guiding the project management process from an initial feasibility study through maintenance of the completed application. Various SDLC approaches include the waterfall model which was the original SDLC method followed by Rapid Application Development (RAD), Joint Application Development (JAD), the Fountain model, the Spiral model; build, fixes and synchronize and stabilized a number of charting methods such as Gantt Chart and Pert Chart and have been developed as tools to create a graphic representation of a project plan and its current status.

\section{Methodology}

The concept of community development derives its strength from two fundamental words namely "community" and "development". The former according to Oduaran (1994:2) implies a group of people or persons in a prescribed locality. The later "denotes an unending improvement in the capacity of groups of individual and societies to control and manipulate the forces of nature as well as themselves for their own material benefits and ultimately for the benefits of the community at large" (Garigiri, 2009:11). Sander (1970:46) identified four ways of conceptualizing community development namely; community development as a process, as a method, as a program and a movement. As a process, community development is viewed as something dealing with the sequences through which communities and their segments go as they advance from traditional to modern forms. In this sense community development advances in stages from one state or condition to the next. It connotes a progression of changes that could be measure using certain specific criteria. For instance it stresses the social relations of the people and the changes that exist in the behavior, attitude and aptitude of such people. Community development has also been viewed as a method that is to say it may be supplemented by such other methods as change by decree of fiat, by the use of different rewards and by formal education. To this end Osuji (1984) advocated for the induction and educational management of that kind of interaction between the community and its people which leads to the improvement of both.

Furthermore, community development has been conceptualized as a program. This has to do with something involving the enacting of a set of procedures in a given goal. Biddle and Biddle (1965) proffered a broader meaning to this when both submitted that emphasis is shifted to how subject specialties like health, welfare, agriculture, industry, recreation etc could be integrated in an effort to promote the development of the people and their communities. The crux of the matter here is on how different sets of activities could be accomplished within a given social milieu.

\section{Findings}

Community development significantly takes the posture of a crusade determined efforts or course to which the people of a community are whole-heartedly committed. Ezeh (1999) conceived community development as a movement designed to produce better living for the whole community with their active involvement and possibly on the initiative of the community members. In the same vein UN (1957) maintained that community development connotes the process by which the efforts of the people themselves are united with those of the governmental authorities to improve the economic, social and cultural life of the people to integrate the community into the life of the nation and to enable them contribute fully in the national progress; in this light, the question of neutrality is ruled out and all members are expected to be actively involved to enhance the quality of living through voluntary efforts and through the participation of individuals and groups in the development proves for the achievement of some definite goals (Ezeh, 1999). Community development is also an effort through which resources could be mobilized and redistributed. It also utilizes an educational process to increase social and political awareness of the causes of their problems, thus empowering them to effectively address those problems. Speight (1973) noted that community development tends to become institutionalized building up its own organizational structures, accepted 
procedures and professional practitioners. He advanced that the goals of community development are essentially broad based focusing on needs like the construction of roads, bridges, markets, stalls, dispensaries etc to non-material needs like making the illiterate people in the community literate, bringing about attitudinal change, reducing maternal and infant mortality rates and averting the incidence of cholera or malnutrition in the community; development project can be measured by examining the extent to which the project has been integrated into national life. Speight was also of the view that we look at other things like increase in per capita income, a decrease in mortality rate, increase in literacy rate, increase in progression of person through the institution of formal education, a lower birth rates, increase in political awareness are empowerment at all levels in the government, increase in rationality of decisions made at the community and national level, rejection of fatalism and defeatism as part of a common existence and an increase rate of voluntary participation in the community and national affairs. Hence, community development is essential in the concept of self-help because it mobilizes the individuals in the community to fully integrate and engage them in the community development projects for a better standard of living and that can sustain the future generation socially and economically in the long run.

\section{Summary and Conclusion}

This sustainable integrated participatory approach has been used by SHUMAS and has been involved in sustainable rural development but believes strongly that isolated actions cannot lead to any meaningful development in the community. In consequence, they adopted the "Integrated Rural Development Approach". This approach is to ensure that beneficiaries contribute in the projects; this participation will ensure project realization and completion and sustainability will be assured as the beneficiaries will acquire some skills during their participation in the project which will help and enable them to manage and maintain the projects after completion and also to help them take development initiatives on their own. Through the participatory approach, SHUMAS has constructed and equipped more than a hundred classrooms in both rural primary and secondary schools in the Far North West, Western and Adamawa Regions of Cameroon. This includes inter-alia government schools like "Kitchu, Ntesimbang, Mejung, Quebessi, Mbokija, Roh Meluf etc etc", Catholic Schools such as "Bamali, Golongui" etc and even Islamic shools like "IPS Bamali" and a host of many other schools. In the sector of Agriculture they have set up integrated Organic Farming training and Demonstration Centers in Kumbo and are training leaders of farming communities and unemployed youths in sustainable agriculture and organic farming which is cost effective and environmentally friendly methods. In the health, water and sanitation domain they have provided portable water to fifteen (15) communities in the thirty (30) village schools in Cameroon over the last two years. She has also continued to make accessible micro credit and micro enterprise to women cooperatives in Cameroon and about Forty (40) women cooperatives are current beneficiaries, with each cooperative made up of an average number of fifty (50) women making a total of 2,250 women.

Furthermore they have collaborated with local councils in replacing eucalyptus trees (detrimental to the soils and water sources) with indigenous and environmental friendly trees species in parts of Bui and Donga Mantung Divisions of the North West Region of Cameroon and protection of water catchments by replacing the 2 million eucalyptus trees with 2.5 million indigenous and water shade trees i.e. agro forestry trees.

\section{End Notes}

Some major difficulties in the implementation of these policies in the various regions amounts to the fact that most of the projects are in rural areas thus follow ups, monitoring is quite ineffective because of accessibility and hampered mobility due to bad or no roads; Delayed or incomplete reports sent by beneficiaries for monitoring. Most at times in a community with people having diversified ideas on ancestral cultures and development has made some to be recalcitrant and they don't want to accept change and development. While some participants will indicate their readiness to participate in the projects while they still remain negligent of the roles they have to play; that is why protocol agreements are signed with beneficiaries defining the role they have to play in the project realization. Thus it has been concluded as at now that there are no any other future approaches to be used in community development other than Sustainable integrated participatory approach which has proven to maintain and guarantee sustainability of projects, community participation is ensured and they strongly believe that isolated actions cannot lead to any meaningful development in a less developed and developing communities.

\section{Biblography / References}


[1] Holland, J and Blackburn, J. (1998) Whose Voice: participatory research and policy change, Intermediate Technology Publications, London.

[2] Larson, P. and Svendsen, D. (1997) Participatory Monitoring and Evaluation, World Wildlife Fund, Washington, DC.

[3] (1998) Participation Works. 21 techniques of community participation for the $21^{\text {st }}$ century. New Economics Foundation, with members of the UK Community participation Network

[4] Pretty, J. and Vodouhe, S. Using rapid or participatory rural appraisal.

[5] Pretty, J., Guijt, I., Scoones, I. and Thompson, J. (1995). A trainer's guide for participatory learning and action. B. IIED

[6] Pretty, J. Guijt, I., Thompson, J. and Scoones, I. (1995) 'Participatory Learning and Action', IIED Participatory Methodology Series IIED, London.

[7] Slocum, R. et al. (1995), Power, Process and Participation: Tools for change, London: Intermediate Technology Publications. 